\title{
Pemanfaatan Vacant Space dan Optimalisasi RTH pada Bundaran Waru
}

\author{
Widya Wahyuning Permata dan Defry Agatha Ardianta \\ Departemen Arsitektur, Fakultas Arsitektur Desain dan Perencanaan, Institut Teknologi Sepuluh Nopember (ITS) \\ e-mail: agathadefry@arch.its.ac.id
}

\begin{abstract}
Abstrak-Vacant space atau lahan kosong cenderung tidak terawat. Kondisi ini menyebabkan pertumbuhan lingkungan yang tidak terkontrol sehingga aktivitas yang terjadi pada lahan ini juga tertutupi dan berpotensi untuk membentuk ruang-ruang negatif. Selain itu, vacant space dapat berupa RTH atau berpotensi menjadi RTH, sehingga memanfaatkan vacant space, agar ruang ini lebih terpantau, juga berpotensi untuk mengurangi RTH. Lahan yang memiliki kriteria dilematis ini contohnya Bundaran Waru. Perancangan pada Bundaran Waru harus menyasar pada aspek sosial dan lingkungan, serta ekonomi agar ruang ini dapat berkelanjutan. Adapun metode yang digunakan adalah metode analogi dan metode arsitektur sebagai lansekap. Alasan pemilihan metode tersebut diharapkan dapat memberikan solusi desain yang spesifik pada lahan Bundaran Waru.
\end{abstract}

Kata Kunci-Bundaran Waru, RTH, Vacant Space.

\section{PENDAHULUAN}

$V_{\mathrm{p}}$ ACANT space adalah lahan kosong. Berdasarkan proses, vacant space terbagi menjadi dua, yaitu lahan yang tetap terbentuknya kosong selama proses pembentukan kota dan bangunan yang pernah ditempati namun pada suatu waktu ditinggalkan sehingga menimbulkan kekosongan. Vacant space adalah bagian dari lingkungan terbangun dimana konstruksi dan aktivitas urban yang terjadi yang mendefinisikan mereka sebagai kosong [1].

Vacant space atau lahan kosong tersebut cenderung tidak terawat. Kondisi ini menyebabkan tumbuhnya vegetasi yang tidak terkontrol. Menurut Hakim dan Utomo, vegetasi mempunyai potensi menjadi penghalang fisik (physical barrier) [2], sehingga mengganggu visibilitas. Salah satu prinsip visibilitas yaitu membuat sesuatu terlihat jelas [3], tidak terdapat pada vacant space, sehingga aktivitas yang terjadi disana tidak dapat terkontrol dan terpantau dengan baik.

Vacant space dapat berupa RTH atau berpotensi menjadi RTH. Salah satu contoh lahan tersebut adalah Bundaran Waru. Bundaran Waru merupakan vacant space yang memiliki image buruk akibat sering terjadinya masalah sosial disana, antara lain fenomena waria dan pembuangan mayat [4]. Hal tersebut dapat diatasi dengan membentuk ruang baru di Bundaran Waru, agar ruang yang ada lebih terkontrol. Namun, membentuk ruang baru berarti juga mengolah lahan, dimana hal ini dapat berpotensi mengurangi RTH. Maka dari itu, halini juga menimbulkan sisi dilematis dalam perancangan, yaitu bagaimana membuat ruang baru yang dapat mengurangi dampak negatif vacant space namun juga tidak mengurangi RTH.

Bundaran Waru juga memiliki kondisi khusus yang berpengaruh pada desain. Posisi Bundaran Waru yang terletak pada simpul jalan arteri (Gambar 1) menyebabkan tapak ini tidak dapat diakses kendaraan bermotor, karena kriteria jalan arteri tidak memungkinkan kendaraan untuk

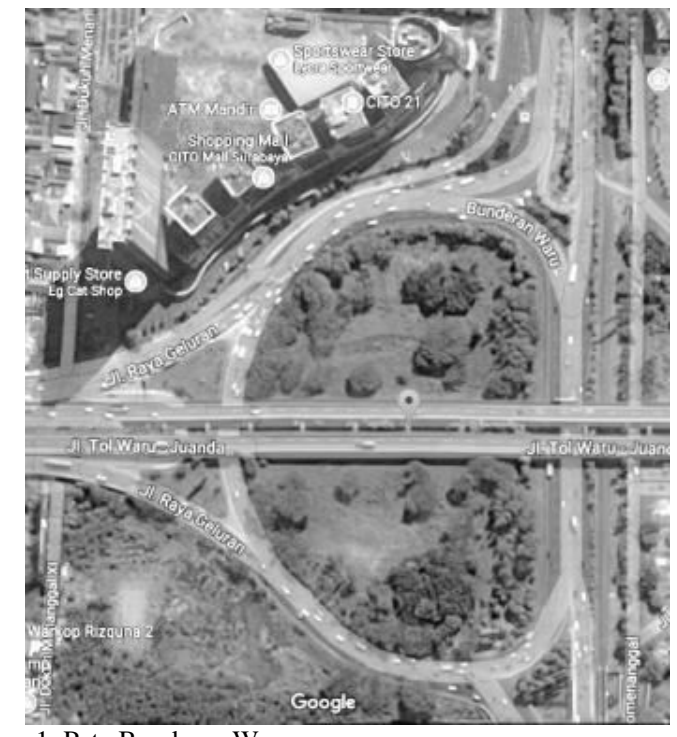

Gambar 1. Peta Bundaran Waru.

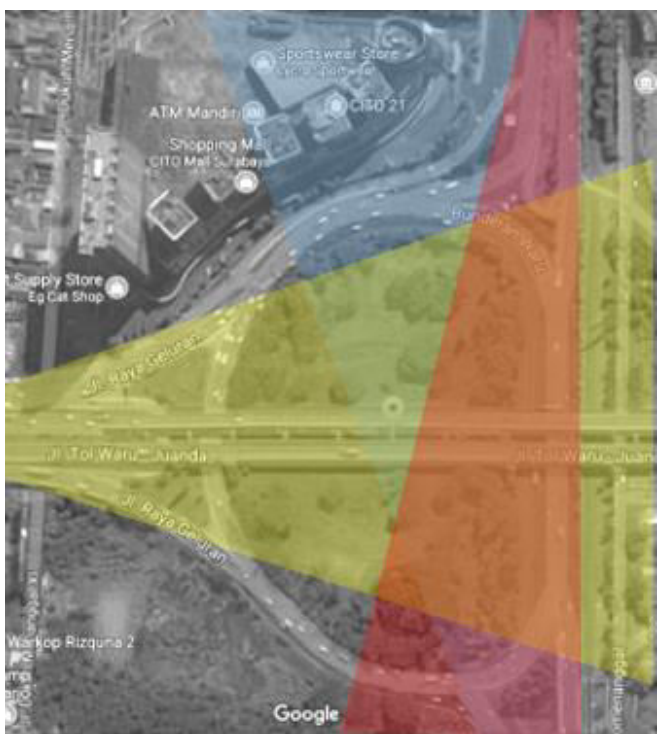

Gambar 2. Diagram Arah Pandang dari Arah Jalan A. Yani, Jalan Geluran dan Jalan Waru.

berhenti dan parkir. Sehingga akses masuk menuju tapak ini yaitu melalui atas jalan raya (sky bridge) atau bawah jalan raya (underpass). Selain itu, Bundaran Waru juga terletak pada wilayah KKOP, yaitu Kawasan di bawah Permukaan Horizontal Luar dimana ketinggian maksimal adalah $145 \mathrm{~m}$ $[5]$.

Bundaran Waru berpotensi menjadi landmark baru untuk gerbang pintu masuk Surabaya (Gambar 2). Ruang baru pada Bundaran Waru dapat berbentuk ruang publik yang mencakup aspek sosial dan ekologi, serta ekonomi agar ruang ini dapat sustain. Program-program yang dihadirkan merupakan rangkuman kebutuhan dari tapak dan warga sekitar, di semua rentang usia. 


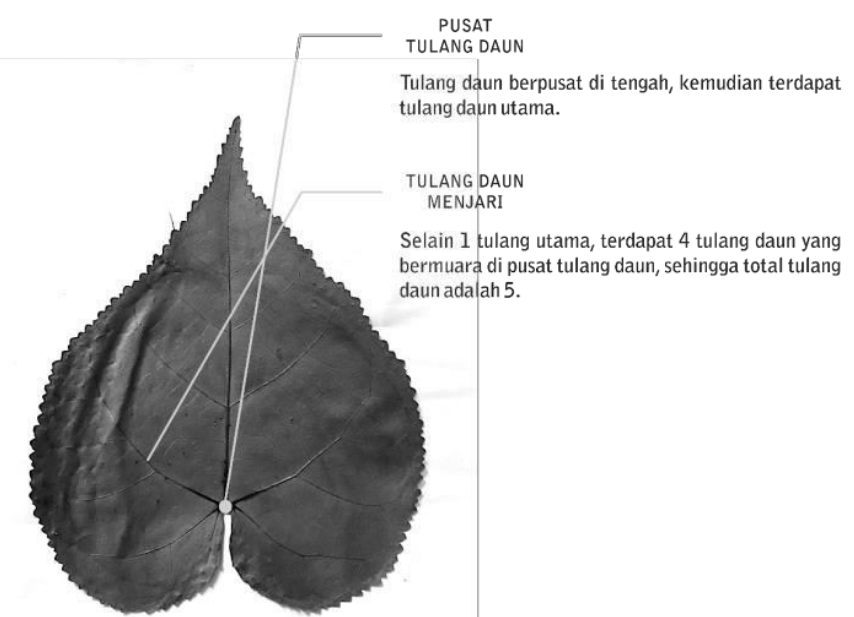

Gambar 3. Penjelasan anatomi daun waru.
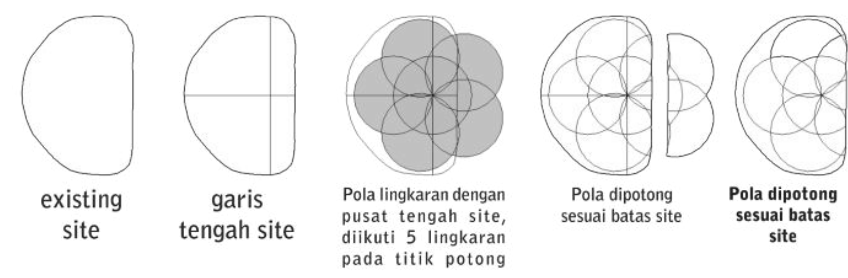

Gambar 4. Diagram konsep site plan.
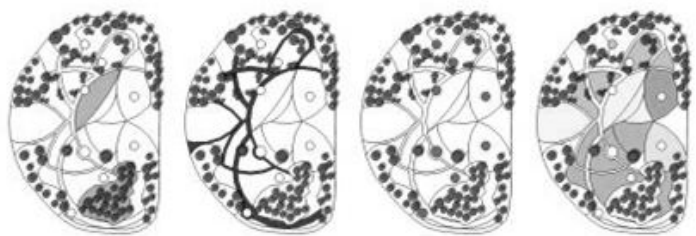

$\begin{array}{cc}\text { Basic } & \text { Spatial form: } \\ \text { form: } & \text { Pengunjung } \\ \text { Me- } & \text { merasakan } \\ \text { manipulasi } & \text { pengalaman } \\ \text { tapak } & \text { ruang dari } \\ & \text { jalur sirkulasi }\end{array}$
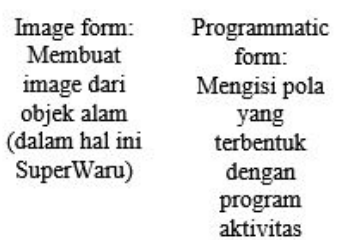

Gambar 5. Layer site plan.

\section{METODE PERANCANGAN}

Metode yang digunakan dalam perancangan adalah metode analogi dan metode arsitektur sebagai lansekap. Metode analogi digunakan untuk menentukan konsep besar sedangkan metode arsitektur sebagai lansekap digunakan untuk pengaturan peletakan program.

Analogi dibagi tiga, yaitu personal analogy, direct analogy dan symbolic analogy [6]. Analogi yang dipakai dalam desain adalah direct analogy dan symbolic analogy. Direct analogy adalah analogi langsung dari fakta-fakta yang ada di alam, dalam hal ini adalah analogi dari daun dan bunga waru yang diambil bentuk dan tatanannya. Sedangkan symbolic analogy adalah analogi tidak langung dari makna yang tersirat, dalam hal ini adalah filosofi tanaman waru yang tumbuh ramah lingkungan. Analogi tersebut bertujuan untuk menciptakan keseimbangan aspek lingkungan dan sosial.

Metode selanjutnya adalah metode arsitektur sebagai lansekap. Metode ini meminjam metode lansekap yang terdiri dari empat layer, yaitu basic form, spatial form, image form dan programmatic form [7]. Basic form adalah kondisi tapak yang dimanipulasi, seperti bukit. Spatial form

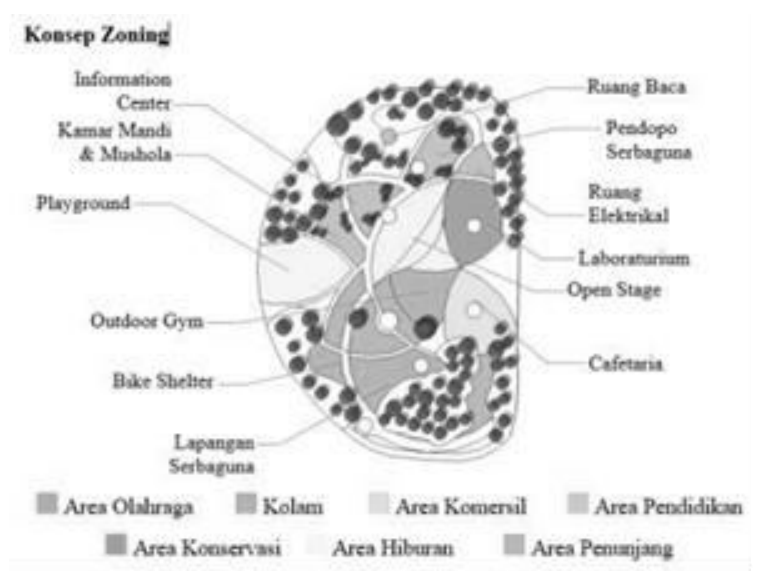

Gambar 6. Konsep zoning.

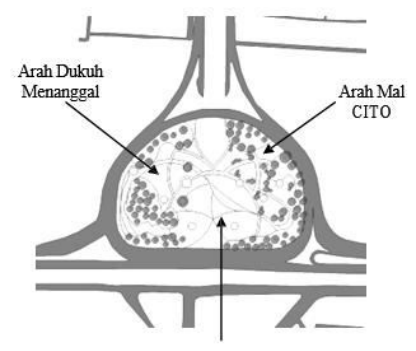

Arah Kerto

Gambar 7. Konsep aksesibilitas dan sirkulasi.

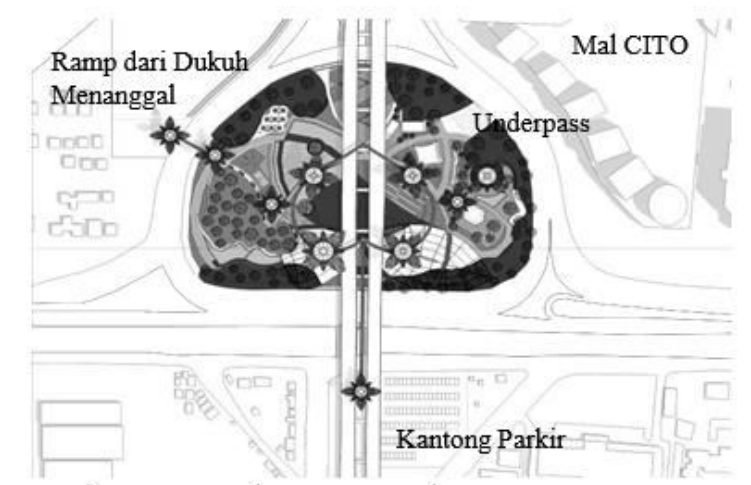

Gambar 8. Master Plan Taman Bundaran Waru.

adalah membuat jalur sirkulasi agar pengunjung dapat merasakan pengalaman ruang. Image form adalah membuat suatu bentukan yang berasal dari bentuk alam, seperti pohon. Programmatic form adalah membuat programprogram pada pola yang terbentuk sebelumnya. Penempatan program juga didasari oleh pertimbangan-pertimbangan dari kondisi eksisting tapak.

\section{HASIL DAN EKSPLORASI}

\section{A. Konsep Site Plan}

Konsep siteplan menggunakan analogi daun Waru (Gambar 3). Tahap dimulai dengan membagi tapak dari garis tengah tapak dengan filosofi keseimbangan (Gambar 4). Keseimbangan yang diharapkan adalah keseimbangan aspek sosial dan lingkungan. Kemudian dilanjutkan dengan tahap membuat 5 pola lingkaran dengan pusat tengah tapak, yang berasal dari bentuk tulang daun Waru yang menjari ( 5 bagian). Setelah terbentuk pola, dilanjutkan dengan membuat layer-layer seperti pada metode arsitektur sebagai lansekap (Gambar 5). 


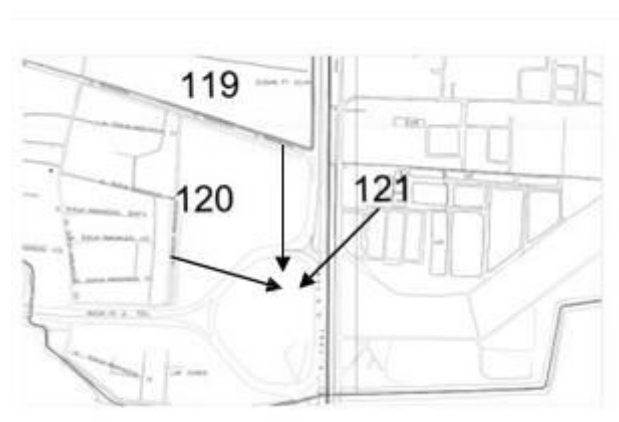

Gambar 9. Peta genangan area sekitar Bundaran Waru [8].

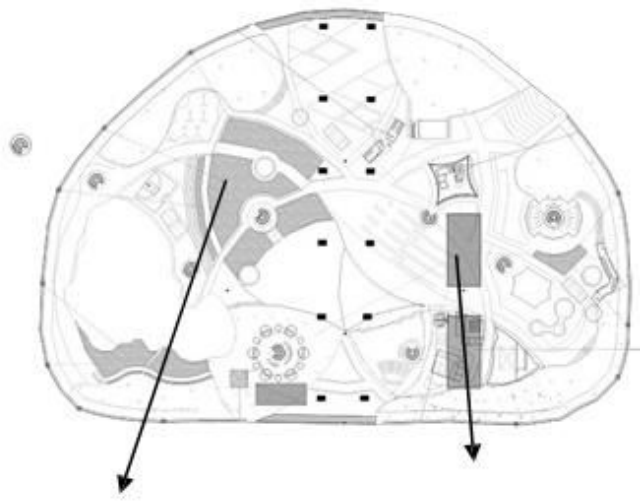

Kolam Retensi

Pengolahan Air Banjir

Gambar 10. Konsep konservasi air.

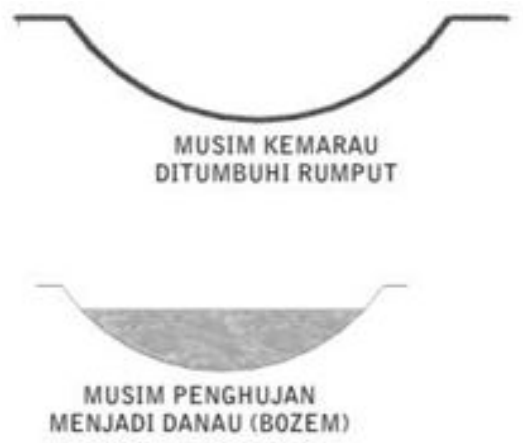

Gambar 11. Konsep kolam retensi.

\section{B. Konsep Zoning dan Tatanan Massa}

Aspek yang diutamakan dalam perancangan Bundaran Waru adalah aspek sosial dan ekologi, serta aspek ekonomi untuk menunjang keberlanjutan ruang publik. Disamping itu, zona- zona terbentuk selain dari alasan diatas, juga berasal dari hasil survei kebutuhan tapak dan warga sekitar.

Zoning yang terbentuk antara lain zona hiburan, olahraga dan pendidikan yang masuk pada aspek sosial, zona komersil yang masuk pada aspek ekonomi, serta kolam dan zona konservasi yang masuk pada aspek lingkungan (Gambar 6). Dari penjabaran zoning tersebut terbentuklah program untuk tipologi bangunan outdoor dan indoor, antara lain lapangan serbaguna, outdoor gym, playground, open stage, ruang baca, laboraturium, cafetaria, supertree (SuperWaru), pendopo serbaguna, information center, bike shelter, mushola dan kamar mandi.

Alasan peletakan program dan zona berasal dari kondisi tapak dan sekitar tapak. Area yang memiliki jumlah pohon banyak akan digunakan sebagai area konservasi sehingga tidak perludilakukan penebangan. Peletakan zona olahraga, yaitu lapangan serbaguna dan outdoor gym, di bagian paling

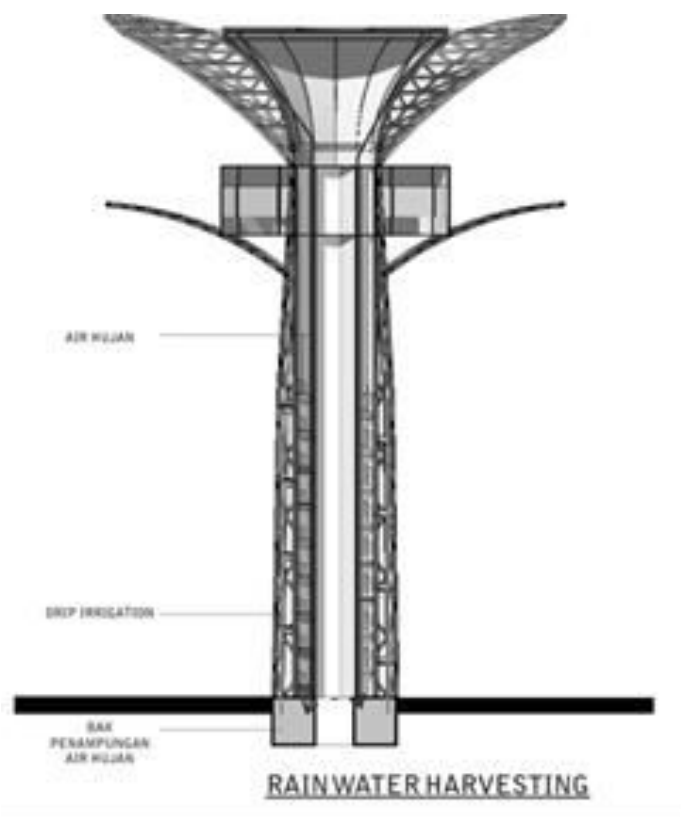

Gambar 12. Konsep rain-water harvesting.

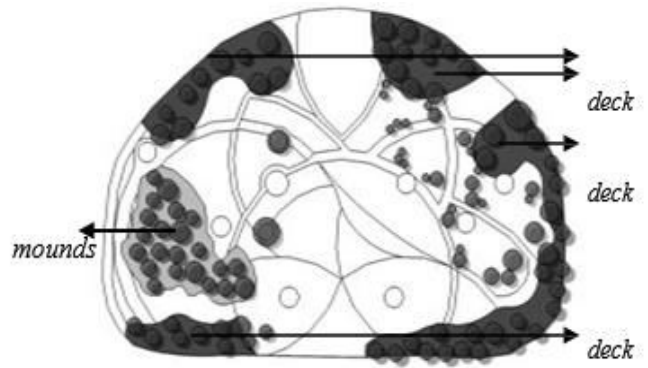

Gambar 13. Konsep mounds and deck.

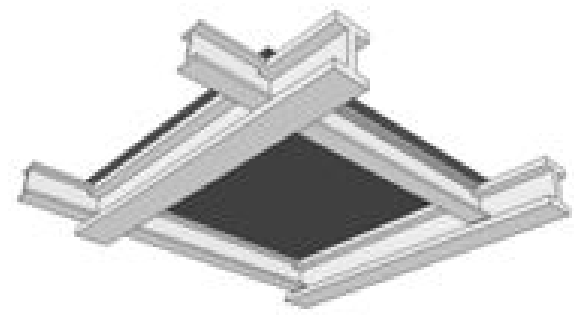

Gambar 14. Grid balok baja.

dekat dengan Dukuh Menanggal karena warga Dukuh Menanggal kekurangan sarana olahraga. Playground diletakkan di bawah jalan tol karena selain area ini cukup luas, juga agar mendapat naungan. Kolam diletakkan pada area-area yang tidak mengganggu struktur jalan layang. Ruang baca diletakkan di dekat kampus UPH karena merupakan sarana pendidikan. Open stage diletakkan ditengah agar pengunjung dari lapangan, playground, outdoor gym, cafetaria, laboraturium dan ruang baca dapat melihat ke arah sini. Cafetaria diletakkan di area perpotongan (Gambar 2) dimana pada area ini terdapat SuperWaru yang paling tinggi, yang juga memiliki tree-top cafe, sehingga area komersil diletakkan pada satu zona. Sedangkan laboraturium diletakkan pada area yang lebih dekat dengan area genangan (Gambar 9).

\section{Konsep Sirkulasi dan Aksesibilitas}

Tapak ini dapat dicapai melalui atas (sky bridge) dan bawah (underpass). Terdapat 3 entrance gate untuk tapak ini, yaitu dari arah Dukuh Menanggal dan Kerto Menanggal yang menggunakan sky bridge dan dari Mal City of Tomorrow yang menggunakan underpass. 
Tabel 1.

Karekateristik Warna [9]

\begin{tabular}{|c|c|c|}
\hline Warna & Efek & Karakter \\
\hline Kuning & $\begin{array}{l}\text { Cerah, menyinari, } \\
\text { periang, }\end{array}$ & $\begin{array}{c}\text { Paling menyenangkan, } \\
\text { hangat, penuh, egosentris dan menyilaukan } \\
\text { ceria }\end{array}$ \\
\hline Jingga & $\begin{array}{l}\text { Menarik, } \\
\text { menstimulus, } \\
\text { menyenangkan } \\
\text { (ceria) }\end{array}$ & $\begin{array}{c}\text { Meng-hidupkan, } \\
\text { enerjik, ceria, periang, ekstrovert, sangat } \\
\text { sosial, lebih lembut dan bersahaja daripada } \\
\text { merah }\end{array}$ \\
\hline Ungu & $\begin{array}{l}\text { Lembut, } \\
\text { menundukkan }\end{array}$ & $\begin{array}{c}\text { Memberi kesan halus } \\
\text { dan kekayaan, memunculkan keresahan dan } \\
\text { penurunan, Eksklusif, bermartabat, } \\
\text { Kesendirian, sedih, angkuh, sombong }\end{array}$ \\
\hline
\end{tabular}

Pengunjung yang berjalan kaki atau membawa sepeda dapat melewati sky bridge dari arah Dukuh Menanggal maupun Kerto Menanggal. Pengunjung dari arah Dukuh Menanggal yang menggunakan transportasi umum dapat berhenti pada halte Waru kemudian berjalan menuju sky bridge. Pada dasarnya, ruang publik ini mengutamakan pejalan kaki, pengguna sepeda dan kendraan umum, namun jika membawa kendaraan bermotor, pengunjung disediakan kantong parkir pada Kerto Menanggal, kemudian masuk melalui sky bridge di sana. Pengunjung juga dapat memarkir kendaraan masing- masing di parkir Mal CITO, kemudian masuk melalui underpass.

\section{Konsep Konservasi}

Ruang publik ini juga mengedepankan aspek ekologi yaitu konservasi. Terdapat beberapa konsep konservasi, seperti recycle air banjir, kolam retensi, rain-water harvesting, deck and mounds dan struktur non-permanen. Konsep recycle air banjir (Gambar 10) ada karena Bundaran Waru merupakan RTH, dimana salah satu kriteria RTH adalah menjaga kawasan resapan air. Saat ini, terdapat beberapa titik genangan pada area sekitar Bundaran Waru, yang terjadi karena saluran kota mengarah ke area Taman Pelangi, sehingga level air yang tinggi lebih lama surut. Konsep recycle air ini adalah penyedotan air banjir di area terdekat Bundaran Waru, kemudian air ini diolah dan digunakan kembali menjadi air kemudian akan dicek kualitasnya sebelum didistribusikan pada Bundaran Waru. Namun, sifat sumber air ini masih merupakan sumber air cadangan, dimana yang utama masih menggunakan PDAM.

Selain pengolahan air pada recycle air banjir, Bundaran Waru juga memfasilitasi luapan air sungai terdekat yang menimbulkan kenaikan level air pada saluran kota. Hal ini sering terjadi saat hujan tiba. Solusinya adalah pada ruang publik Bundaran Waru ini akan diberi pintu-pintu air yang terhubung pada saluran kota di sekeliling Bundaran Waru. Pintu air ini akan terbuka jika volume air sudah tinggi, kemudian air akan dialirkan pada kolam retensi (Gambar 11), namun sebelumnya akan difilter terlebih dahulu. Konsep kolam retensi ini adalah kolam dengan kedalaman maksimal1,5 m, yang jika musim hujan ia akan menjadi kolam dan jika musim kemarau air akan surut, kolam menjadi lembah yang ditumbuhi rumput.

Terdapat pula konsep rain-water harvesting (Gambar 12) pada masing-masing SuperWaru. Pada bagian atas SuperWaru terdapat pipa-pipa air yang mengalirkan air hujan untuk ditampung di tangki bawah. Air ini kemudian akan digunakan kembali untuk menyiram tanaman di sekeliling SuperWaru. Kemudian pada area dengan jumlah

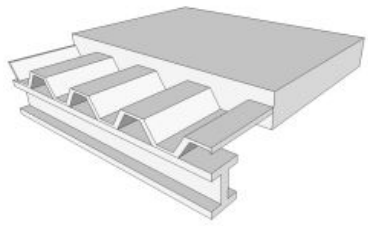

Gambar 15. Floor deck.

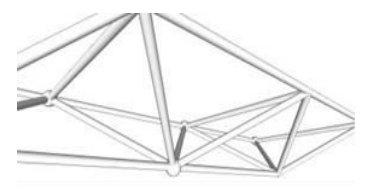

Gambar 16. Ball Joint.

pohon yang rimbun akan menjadi wilayah konservasi. Maksudnya disini adalah konservasi area resapan air hujan. Pada area terluar, dibuat deck yaitu plat dengan struktur kolom baja yang dilubangi sesuai area pohon. Tujuannya selain sebagai konservasi tanah, juga sebagai pagar pembatas tapak. Kemudian pada area dalam, dibuat mounds yaitu meninggikan permukaan tanah kemudian bagian terluar diberi dinding penahan (seperti pot). Dinding ini dapat dimanfaatkan sebagai wall climbing. Pertimbangan mengapa area mounds tidak dibuat deck karena pohon di area ini lebih rimbun. Jika dibuat deck, maka dapat memicu aktivitas negatif. Maka dari itu dibuat mounds yang permukaan atasnya tidak dapat diakses (Gambar 13).

Massa-massa yang hadir pada Bundaran Waru menggunakan struktur non-permanen. Laboraturium, cafetaria, outdoor gym, open stage, ruang baca, mushola, information center, pendopo dan kamar mandi menggunakan sistem panggung. Struktur menggunakan kolom baja dengan pondasi setempat, grid balok baja dan floor deck, untuk atap menggunakan space frame dengan ball joint dan penutup atap berupa alumunium composite panel. Sedangkan struktur SuperWaru menggunakan frame baja untuk selubung dan core menggunakan precast reinforce concrete. Penggunaan struktur pada massa-massa ini bertujuan agar beban yang diberikan pada tanah lebih ringan.

\section{E. Konsep Warna}

Selain mengedepankan aspek ekologi, ruang publik ini juga mengedepankan aspek sosial. Hal ini bertujuan agar perilaku apapun yang terjadi di Bundaran Waru merupakan perilaku positif. Warna merupakan salah satu faktor pembentuk perilaku. Konsep warna yang diambil berasal dari spektrum bunga waru yaitu kuning-jingga-ungu tua. Karakteristik warna dapat dilihat pada Tabel 1 [9].

Dari penjabaran Tabel 1, disimpulkan bahwa warna jingga dipilih untuk warna makro dalam desain, dimana dipakai untuk SuperWaru, massa yang paling dominan. Warna jingga dipilih karena memberikan efek psikologis yang positif sehingga diharapkan perilaku yang terbentuk pada Bundaran Waru juga positif.

\section{KESIMPULAN}

Penanganan masalah yang timbul pada vacant space, khususnya Bundaran Waru dapat diatasi dengan mengedepankan aspek sosial dan lingkungan. Aspek lingkungan diperlukan agar tidak mengurangi RTH, namun mengoptimalkannya. Konsep tanaman waru dipilih agar terjalin keseimbangan aspek sosial dan lingkungan dalam 
desain. Selain itu, terdapat aspek ekonomi agar ruang publik yang tercipta dapat lebih sustain.

Keberadaan ruang publik pada Bundaran Waru nantinya akan meningkatkan fungsi RTH, yang pada awalnya hanya paru-paru kota sebagai dengan tanah sebagai serapan air minimal, akan menjadi penampung air dan buangan air pada kawasan yang tergenang saat puncak musim hujan. Dengan demikian, ruang publik ini dapat menjadi kunci pemecahan masalah banjir untuk area sekitar Bundaran Waru.

\section{DAFTAR PUSTAKA}

[1] M. Nefs, "Unused Urban Space: Conservation or Transformation? Polemics about the Future of Urban Wasteland and Abandoned Buildings," City Time, vol. 2, no. 1, pp. 47-58, 2006.

[2] R. Hakim and H. Utomo, Komponen Perancangan Arsitektur Lansekap: Prinsip - Unsur dan Aplikasi Desain. Jakarta: Bumi
Aksara, 2003

[3] J. Preece, Y. Rogers, and H. Sharp, Interaction Design: Beyond Human-Computer Interaction. New York: John Wiley \& Sons Inc, 2002.

[4] R. Priyonggo, "Terbungkam Kain Biru Ditemukan Tewas di Bundaran Waru," 2017. [Online]. Available: beritajatim.com.

[5] Menteri Perhubungan Republik Indonesia, "Keputusan Menteri Perhubungan tentang Kawasan Keselamatan Operasional Penerbangan di Sekitar Bandar Udara Juanda - Surabaya, No. 5," 2004.

[6] G. Broadbent, Design in Architecture. Architecture and the Human Sciences. London: John Wiley \& Sons Inc, 1973.

[7] D. Jauslin, "Architecture with Landscape Methods Case Study of the Rolex Learning Centre Lausanne by SANAA Tokyo," in Proceedings of the 8th ISAIA, 2010, pp. 162-165.

[8] BAPPEKO Surabaya, "Peta Genangan Surabaya Selatan Wilayah sekitar Bundaran Waru."

[9] F. H. Mahnke and M. R.H., Color and Lighting in Man-made Environtment. New York: Von Nostrand Reinhold Company, 1987. 